\title{
ARTICULAÇÕES DA POLÍTICA (NEO) LIBERAL E SEUS IMPACTOS NA EDUCAÇÃO
}

\section{JOINT POLICY (NEO) LIBERAL AND ITS IMPACTS ON EDUCATION}

\author{
Luciana Belissimo Carvalho ${ }^{1}$ \\ Elenir Machado de Melo ${ }^{2}$
}

\begin{abstract}
Resumo: O objetivo do estudo visa a compreender a educação (sentido genérico) e sua relação com a política (neo) liberal e em decorrência o processo de emancipação humana. Para tanto, torna-se inescusável traçar um plano de investigação analítica no que concerne à sua base de sustentação, em outras palavras, seus determinantes sócio-políticos oriundos das imposições liberais. Para tanto, a metodologia respalda-se na pesquisa bibliográfica com ênfase no materialismo histórico dialético. Destarte, o trabalho traz como escopo precípuo a elucidação dos fatores e relações que se engendram no interior da lógica liberal que, por sua vez, influenciam na forma em que a educação se estabelece e quais fins se propõem.
\end{abstract}

Palavras-chave: Liberalismo. Educação. Emancipação Humana.

Abstract: The goal of this study aims to understand the education (generic sense) and its relationship with politics (neo) liberal and due process of human emancipation. Therefore, it turns inexcusable outline a plan of analytic investigation with regard to its support. In other words, their socio-political determinants of the liberal's charges. For this, the methodology draws upon literature with emphasis on the historical and dialectical materialism. Thus, the work brings major duty as the scope and the factors' elucidation and relations that engenders within liberal logic, in turn, influence the education's way as it is established and the purposes of it.

Keywords: Liberalism. Education. Human Emancipation

\section{Introdução}

Ao versar pelo lema "liberdade e igualdade a todos", o Estado liberal burguês busca alternativas via educação à resolução dos impasses imanentes a sua própria natureza excludente, posto que, amiúde contornam os problemas oriundos da luta entre as classes com interesses antagônicos em função do capital e do lucro, categorias antitéticas à emancipação das classes populares, menos favorecidas economicamente. Nesta perspectiva, o liberalismo, e mais recentemente o neoliberalismo designa a democracia como instrumento eficaz na consolidação dos diretos dos cidadãos. Em síntese, constata-se que a educação dentro deste contexto de contradições se constitui em fator de monopólio de massa, contribuindo para a estratificação social ao ser predeterminada pela classe dominante, desmobilizando o homem e impedindo sua emancipação.

Ante o assunto devemos compreender tal processo em sua gênese: as bases do liberalismo clássico tomadas como um fator imprescindível para o entendimento e

\footnotetext{
${ }^{1}$ Pós-graduanda em Ed. Infantil-UFMS/CPAQ.

${ }^{2}$ Professora Mestre Adjunta do Departamento de Educação da UFMS/CPAQ. 
compreensão dos fundamentos teóricos e metodológicos que perpassam e ancoram as propostas educacionais brasileiras. Partindo desse pressuposto procede-se a uma investigação teórica no que se refere ao conceito de liberalismo, sua origem, principais teóricos, estruturação, características e crises (LIMA, 2008).

Para alcançar esse escopo, visualizam-se tais questões à luz da teoria do materialismo histórico dialético, que por sua vez, confere um caráter heurístico, ou seja, o mérito prevalecente será o da descoberta da verdade histórica numa visão dialética da dinâmica social.

De acordo com essa concepção, o liberalismo não pode ser visto como um conjunto de idéias deslocado da realidade, e sim uma ideologia da sociedade burguesa, resultante da materialidade das ações do homem.

\section{Liberalismo}

A terminologia liberalismo pode ser definida como um conjunto de idéias que tem a finalidade de garantir a liberdade individual e a propriedade privada. Sob esta ótica, Bobbio concebe o estado liberal como assegurador dos direitos naturais e invioláveis do indivíduo (BOBBIO, 1992; 2000).

No que se refere aos direitos naturais do indivíduo, assevera Bobbio:

[...] O direito natural (ou jusnaturalismo): doutrina segundo a qual o homem, todos os homens, indiscriminadamente, têm por natureza e, portanto, independentemente de sua própria vontade, e menos ainda da vontade de alguns poucos ou de apenas um, certos direitos fundamentais, como o direito à vida, à liberdade, à segurança, à felicidade - direitos esses que o Estado, ou mais concretamente aqueles que num determinado momento histórico detêm o poder legítimo de exercer a força para obter a obediência a seus comandos devem respeitar, e portanto não invadir, e ao mesmo tempo proteger contra toda e possível invasão por parte dos outros (BOBBIO, 1988, p. 19).

Verifica-se que o desiderato da burguesia enquanto classe hegemônica desde o advento da Revolução Francesa (1789) até a atualidade, reside exatamente no fato de que todo homem deve ter sua individualidade respeitada, sendo, então, todos iguais e, portanto, possuidores de direitos naturais e irrevogáveis. A burguesia criou as idéias liberais para justificar o novo modo de produção - o capitalismo, abrindo horizontes ao suprimir a ordem medieval.

O elemento basilar dessa nova classe social constitui-se na defesa de liberdades comerciais, liberdade para vender e comprar mercadorias, livre das restrições impostas pelo Antigo Regime. Lançam-se, assim, as primeiras bases para a expansão do mundo do capital.

A partir desse momento a burguesia torna-se a classe dominante com expressiva ascensão econômico-ideológica subjugando as demais classes.

A partir desse quadro geral do liberalismo é possível desvendar a sua real essência. Consequentemente, em consonância com tal lógica, a educação é concebida amiúde como algo capaz de mudar a realidade social, política e, inclusive, a econômica contribuindo à emancipação humana (liberdade e igualdade), uma concepção oriunda e própria do ideário liberal.

Para compreendermos criticamente essa afirmativa liberal, é de suma importância tecer considerações mais aprofundadas. Ao elencar esse parâmetro, como base primeira no que diz respeito a essa análise, visa-se a demonstrar que a educação é determinada 


\section{INTERFACES DA EDUCAÇÃO}

socialmente pelas relações de produção, girando em torno das relações sociais estabelecidas. Portanto, fator resultante da base material do capital, isto é, vinculada às demandas da sociedade de classes que, por sua vez, se caracteriza por aspectos excludentes e contraditórios.

No caso particular, o liberalismo se impõe como elemento determinante da organização das sociedades complexas atuais, ou seja, analisa-se, embora que de maneira não exaustiva, a nova configuração social instaurada a partir do modelo liberal burguês, e, no bojo dessa conjuntura política a situação educacional. Constata-se que o modelo liberal de sociedade surgiu como justificativa constituída de preceitos no plano ideológico, político, ético, econômico e educacional, baseado em condições de liberdade e igualdade a todos, em contraposição ao Antigo Regime imperante durante a Idade Média.

Portanto, trata-se de apreender a materialidade histórica dos fatos, com o intuito de vislumbrar a hegemonia superestrutural do ideário liberal e suas implicações no âmbito educacional - fator que vem causando a fragmentação do sistema de educação e, por conseguinte, a defasagem no processo de conhecimento baseado no positivismo e linearidade dos fatos.

Neste sentido, a preocupação precípua reside em traçar um plano de análise cuja leitura da realidade não se caracterize pela inversão da realidade, haja vista, as expressões superestruturais das relações sociais como elementos basilares a exclusão e as desigualdades produtos do capitalismo.

Ao depreendermos destas questões, descarta-se a concepção de que a educação em si mesma encerra e constitui-se num instrumento capaz de corrigir as mazelas, de ampliar as condições de liberdade e igualdade às classes populares, mas um princípio resultante das contradições da realidade multifacetada pelos interesses antagônicos das mais distintas classes que, por sua vez, revelam-se cada vez mais desmobilizadas em razão do recrudescimento do capital sob o controle da minoria dominante.

Abordar a educação como prática social requer a busca pela compreensão da base material que lhe da sustentação, isto é, seus determinantes sócio-políticos, no caso particular, as contradições oriundas do neoliberalismo e suas implicações. Na atualidade, em especial, no Brasil, tratar das questões e impasses (inadequações das políticas públicas) que envolvem a educação como área estratégica de manipulação das massas e de mantenedora da hegemonia da classe dominante, significa ter por meta um plano abrangente de investigação da lógica do Estado mínimo, globalização e livre mercado.

Numa primeira instância se faz necessário vislumbrar a forma pela qual a sociedade se organiza e se estrutura. De acordo com Marx, (1998) isso se dá pela formação da base econômica - conjunto de relações de produção e o grau de desenvolvimento que lhe corresponde, e esse fator será responsável pelo estabelecimento das instituições políticas e jurídicas, isto é, a superestrutura, a qual corresponde às formas de consciência social. Contudo, partir de tal vislumbre da sociedade, em linhas gerais, requer uma ressalva, pois conforme a teoria marxiana, faz-se necessário analisar os fatos e fenômenos, isto é, a realidade em si, de maneira dialética em sua interdependência, pois do contrário, não se compreende os fenômenos sociais, enfim a história partindo das idéias, e sim da materialidade, das lutas de classes.

Para suprir suas necessidades o homem produz bens necessários para prover a vida e esse fator ira determinar a política, a qual, numa relação dialética gera influxo sobre a sociedade.

Diante dessa perspectiva, cabe enfatizar que a educação pela forma que se estabelece (consonância com as políticas neoliberais) é determinada pelas relações sociais de produção, fazendo parte da superestrutura da sociedade. 


\title{
INTERFACES DA EDUCAÇÃO
}

\section{Neoliberalismo}

Observa-se que o neoliberalismo constitui na atualidade a política de orientação governamental. Caracteriza-se como uma reforma do ideário burguês clássico em prol das exigências do capital em seu decurso acidentado. Para Azevedo,

\begin{abstract}
Neste processo, o estado liberal burguês passa a incorporar uma nova dimensão de legitimidade: a igualdade passa pelo alargamento dos direitos políticos dos cidadãos, proclamado como meio de garantir a participação no poder e o seu controle, fundamentado e organizado na forma de uma democracia (AZEVEDO, 2001, p. 9).
\end{abstract}

O neoliberalismo se traduz em uma ordem social, política e econômica que visa a estabelecer o Estado Mínimo na focalização de apologias à privatização dos serviços públicos, por exemplo, no setor da saúde e da educação, e descentralização como alavanca central de democratização e eficiência.

Ao verificar tais propugnações da vertente neoliberal, Frigotto (1994) assinala que na vida prática, a descentralização se constitui em um processo antidemocrático, ao passo que delega às empresas públicas ou privadas, aos Estados e aos municípios e, inclusive, à comunidade, a manutenção da educação básica. Desta forma, o Estado se exime de gastos com o sistema público havendo uma espécie de transferência da responsabilidade estatal à esfera privada como meio proeminente à regulação e ao auto-ajuste do mercado, o que propicia a verdadeira equidade social.

Uma das primeiras tentativas para se entender o caos em que se vive hoje na produção da vida material, nas relações de trabalho como produto de uma síntese de múltiplas determinações, torna-se imprescindível à busca pelo ponto de origem da corrente neoliberal, idéias que surgem para justificar tais formas de relações. Torna-se inescusável traçar um plano mesmo que resumido a fim de estabelecer uma análise mais próxima da totalidade do fato.

Como visto, as explanações precedentes revelam que a teoria neoliberal se caracteriza por uma adaptação ou reforma em função das mudanças ocorridas durante a trajetória do capital. Tem sua base de apoio no liberalismo clássico do século 17, de ideais firmados na exacerbação do individualismo como realização plena do homem, Estado Mínimo e independência do mercado como condição para o pleno desenvolvimento social.

Nesta fase (nova roupagem), o Estado liberal burguês reúne um novo conjunto de concepções relativas à regulamentação da sociedade de modo geral. Passa por um redimensionamento da legitimidade, que prevê a igualdade interligada com a ampliação de direitos políticos, defendido como caminho eficaz na garantia da participação política no que concerne ao poder e seu controle, estruturado de forma democrática.

Neste momento de reordenação do Estado burguês verifica-se que houve em todos os aspectos da vida social, de forma constante e com certa veemência, a luta travada por meio das propugnações imanentes ao bojo liberal, almejando manter viva a base da máxima liberal, ou como preferem alguns, neoliberal: "Mais mercado, menos Estado"; a independência do mercado na preservação do capital.

Conforme o ideário neoliberal, a função do Estado deve se restringir à função de guardião dos interesses públicos. Diante desta visão a educação é concebida como um dos bens essenciais pelos quais, assiste ao Estado o seu provimento. Em contrapartida, faz parte da política neoliberal a privatização do ensino - fator que vai ao encontro das relações de 


\title{
INTERFACES DA EDUCAÇÃO
}

mercado, e, nesse contexto a educação se integra como um grande negócio, adquirindo um caráter mercadológico.

Para não perder o fio condutor das raízes neoliberalizantes, Azevedo faz uma referência aos mecanismos de recomposição do Estado burguês.

\begin{abstract}
Incorporando os argumentos de Adam Smith, Jeremy Benthan e as formulações de James Mill, a concepção "utilitarista de democracia" concebe a condução da atividade econômica pela "mão invisível" do mercado como uma condição apropriada à maximização do bem-estar. Os fundamentos da liberdade e do individualismo são tomados aqui para justificar o mercado como regulador e distribuidor da riqueza e da renda, compreendendo-se que, na medida em que potencializa as habilidades e a competitividade individuais, possibilitando a busca ilimitada do ganho, o mercado produz, inexoravelmente, o bem-estar social (AZEVEDO, 2001, p. 9-10).
\end{abstract}

Contudo, esta acepção bastante expressiva no século 19, foi se definhando em detrimento da própria lógica do desenvolvimento do capitalismo. Dentre muitas novas formas de transformações, encontra-se a "crescente organização do trabalho, a veiculação do ideário socialista; o progresso técnico e científico; a crise de 1870; a revolução de 1917; a recessão de 1930; as duas grandes guerras; os reordenamentos políticos e sociais; a redefinição do espaço internacional" (AZEVEDO, 2001, p.10).

Esses fatores foram responsáveis por impelir o estabelecimento da concretização de novas formas de articulação entre o Estado e o mercado, adquirindo outras metas via arregimentação das estratégias com o objetivo de se ajustar a um padrão e/ou base técnica diferenciada para a acumulação, regulação do capital e até mesmo das formas de se desenvolver o trabalho como um todo.

Quanto a esta acepção, Frigotto (1994) em suas formulações, evidencia que os homens de negócio aspiram por um novo trabalhador, uma nova qualificação, uma vez que diante da reestruturação econômica assentada sob uma nova base técnica, possibilitando, dessa forma, lidar com a tecnologia, convertendo-a na direção da possibilidade de se tornarem extremamente competitivos no campo dos percalços envoltos à concorrência intercapitalista.

Com e existência dos entraves (crises e recessões) oriundos do próprio funcionamento do mundo capitalista ao longo dos séculos 19 e 20, a teoria política de restabelecimento da estrutura orgânica dessa sociedade predominou de modo a interceptar a derrocada e a exaustão do mundo liberal burguês. Constata-se que tal reordenação acompanhou todo essa trajetória de desníveis e "encontrou espaço propício para se revigorar na crise econômica dos anos 70, quando assumiu a versão que tem sido denominada de neoliberal" (AZEVEDO, 2001, p. 10).

Segundo Orso (2007) a corrente neoliberal tem sua base de apoio nas proposições formuladas por Friederich Hayek (1899-1992) e Milton Friedman (1912- 2006), seus principais ideólogos, que influenciam as políticas sociais fortemente a partir da segunda metade da década de 1970, se amplificando até o século 21.

O neoliberalismo se interpõe ao próprio modo de organização social e político originado no seio do Estado liberal burguês, ou seja, põem em xeque as medidas intervencionistas, articula novas proposições para manter vivo o capital e suas determinações. Suas teses principais são definidas pela apologia ao individualismo e à liberdade, conforme as antigas postulações impressas pelo liberalismo clássico.

A liberdade impetrada pela teoria neoliberal implica em um plano que pressupõe que cada indivíduo, "tenha assegurada uma esfera privada, que exista certo conjunto de 
circunstâncias no quais outros não podem interferir" (HAYEK, 1983 apud AZEVEDO, 2001, p. 11). Nesse sentido,

De acordo com Hayek, a sociedade vai selecionando e escolhendo aos melhores caminhos, "natural" e "espontaneamente". Nessas condições, indivíduo e mercado confundem-se, e a sociedade aparece como resultado de um acordo espontâneo de vontades livres. Para ele as instituições, dentre elas o mercado, surgem e evoluem espontaneamente. Se os homens pensam que são capazes de conhecer a realidade e ousam tentar planejar e reconstruir a sociedade, acabam incorrendo no erro de, sonhando como o paraíso, pavimentarem "o caminho da servidão" (ORSO, 2007, p. 173).

\section{Panorama geral de submissão e dependência do setor educacional às políticas neoliberais}

As políticas públicas alusivas às questões educacionais constituem, por sua vez, em uma ação política de dominação, fator que acentua a estratificação social e reconstrói a hegemonia de classes. Quanto a isso, Azevedo (2001) adverte: tais políticas possuem um caráter de dominação que se expressa nas práticas sociais, nos contextos de relações sociais plasmadas pelas assimetrias, exclusão e desigualdades que se concretizam no plano social.

Pode-se verificar a conservação da ordem vigente via educação, que amiúde é estabelecida pelas políticas neoliberais de cunho voltado à manutenção do capital e suas exigências.

A relação entre o Estado, sociedade e mercado, não podem ser considerados como algo invisível e/ou novo, e sim, uma conexão intrínseca que se revela explicitamente por meio da alarmante e crescente pobreza, desemprego estrutural e violência, o que contradiz as promessas de condição humana digna a todos os cidadãos, tão propalada pelo ideário democrático burguês, concernente a ampliação da igualdade e liberdade a todos via educação - elemento propulsor desse acesso.

Azevedo (2001) no Prefácio à segunda edição é bastante categórica ao afirmar que a ação da política neoliberal resulta em um poder de persuasão em razão de escamotear os processos sociais (a raiz dos problemas, das mazelas) decorrentes dessa nova roupagem da qual se veste o capital em escala mundial.

Neste contexto, é expressiva a forma de que se dispõe a vertente neoliberal como um sistema de ordem político-social em face da exclusão social espargida por todo o planeta, exaurindo as grandes promessas de liberdade e igualdade; processo desencadeado pelas obviedades do capitalismo, que exacerba a polarização das desigualdades - de um lado concentra a riqueza e de outro a crescente pobreza.

Contudo, na tentativa de reduzir os problemas da marginalização social, o Estado liberal atua em sua forma assistencialista ao prover as condições mínimas de sobrevivência mediante programas e projetos, e o setor educacional não poderia passar despercebido, uma vez que se constitui em um cenário privilegiado à aplicação das políticas de ajuste neoliberal como possibilidade de mudar a realidade pautada pelas desigualdades sociais.

O neoliberalismo, na função de marco de referência, conduz e orienta a tomada de decisão governamental em todos os níveis, concebendo a educação como meio eficaz para a redução das desigualdades sociais.

Para tanto, viabiliza formas assistencialistas no sentido de sanar as necessidades mais prementes em curto prazo, por exemplo, programas que proporcionam o acesso à educação 
(bolsa escola, entre outros) como via de escape para se obter a "emancipação humana" intrínseca ao domínio do mercado. Neste sentido, pergunta-se: A educação em si liberta?

É possível constatar a razão pelas quais os programas e projetos sociais do governo são aceitos e até mesmo aplaudidos pelas classes populares, uma vez que tratam os problemas sociais por meio de medidas paliativas. Haja vista, sanam as necessidades eminentes da população em curto prazo. A título de exemplificação, observa-se o que ocorre com a educação em nome da "democracia". A política educacional na atualidade tem base na descentralização, flexibilização e especialização do setor (Oliveira, 2007).

Assim, passa-se da visão macro do governo federal, para políticas localizadas e específicas, de acordo com as diversas regiões. Diante disso, os problemas que afetam o processo de escolarização serão mais fáceis de contornar, visto que, estão sob a égide do poder local, da comunidade e dos setores produtivos.

Agora, o que predomina, é a participação de todos na gestão da educação, e não mais políticas previamente determinadas pelo governo federal. A ênfase reside na descentralização democrática.

Uma questão que merece destaque, estabelecida no contexto dessa nova reestruturação da educação é o suporte que tais políticas liberais encontram no âmbito social, inclusive por parte de estudiosos das ciências humanas.

A descentralização potencializa a identificação de cada município, aumentando os resultados das ações realizadas. Possibilita também a criação de soluções alternativas com base nas características da comunidade local. [...] Uma das tendências da gestão educacional é a busca de alternativas que se adequem às necessidades de cada localidade. E como saber quais são as necessidades? Como melhor atendê-las? Essas perguntas constantes no processo de planejamento da educação de políticas educacionais só podem ser respondidas por meio da proximidade entre os órgãos municipais e a comunidade local. A participação da comunidade torna-se peça vital no levantamento das necessidades e na verificação no impacto das ações. [...] A gestão democrática da educação busca a criação de uma gestão compartilhada, na qual não só o governo é responsável pelas definições, mas também todos aqueles envolvidos com a questão da gestão da educação. A aproximação entre Estado, professores, diretores, alunos, pais e outros possibilitam uma melhoria de qualidade de ensino e uma maximização de resultados. Um exemplo é o projeto Amigos da Escola, que chama a comunidade para a escola, ajudando-a a melhorar a sua infra-estrutura e possibilitando a interação com a comunidade (OLIVEIRA, 2007, p. 57-60).

Porém, o que não se põe em prática, é uma linha de ação comprometida com a subversão da ordem imposta. Continua-se, a disseminar uma cultura de camuflagens momentâneas, que consolida um estado de dormência no que diz respeito aos impasses sociais, suas implicações e antagonismos, a fim de provitalizar o capitalismo.

Essa posição governamental conduz a sociedade a um processo cada vez mais antidemocrático, pois não está vinculada a um plano de caráter subversivo da excludente ordem imposta, mas conservador de sua base de sustentação - o capitalismo.

Como regra, as políticas neoliberais postulam a contenção de gastos governamentais estabelecendo a privatização dos serviços públicos básicos, entre os quais estão os sistemas de saúde, segurança, transporte e educação, e, à medida que essa tarefa é incumbida à esfera privada e à livre iniciativa, verifica-se a atribuição à comunidade em geral do encargo referente a esses serviços, isto é, sua manutenção direta. 


\begin{abstract}
Qualquer que seja a razão, o encargo das "comunidades" na manutenção direta da escola "comunitária" que se pretende pública decorre da ausência do Estado. Esta ausência pode resultar da omissão do próprio Estado, que não dá a devida importância à obrigação legal de universalizar o ensino, mediante o que se processa a elevação do nível cultural das massas e a ampliação de uma das condições da cidadania. Para ocupar esse vácuo, sugiram várias iniciativas "comunitárias" oferecendo ensino às crianças, adolescentes e adultos das classes populares, assim como os meios de comunicação de massa, principalmente as emissoras comerciais de TV, que se especializam na inculcação ideológica via novelas, noticiários, filmes e outros programas, sem falar dos anúncios, que se esmeram nesse propósito (CUNHA, 2001, p. 388)
\end{abstract}

O Estado, sob as imposições neoliberais no âmbito de seus interesses, induz por meio de incentivos à iniciativa privada a administração da educação escolar, que se pretende pública em termos legais. Pois o escopo do Estado acerca desta estratégia política possui um caráter bilateral que se categoriza em:

I) Cooptar as lideranças, fazendo-as intermediárias entre as demandas e as "realizações" do governo, intermediação essa muito útil para atenuar as pressões imediatas, e para efeito eleitoral. II) Diminuir os gastos com os serviços públicos demandados pela população de baixa renda, que é chamada a entrar com parte dos recursos (principalmente a força de trabalho, mediante a valorização do "mutirão" e outras formas de auto-ajuda) e a diminuir as expectativas de qualidade e amplitude dos serviços pretendidos, que devem ficar "no nível da comunidade" (CUNHA, 2001, p. 389).

Após delinear o panorama ao qual está submetida à educação no século 21 , chega-se a constatação de que o Estado induz as "comunidades" a concordar com uma educação barateada em termos pedagógicos e financeiros, fator que reforça os "padrões" de cunho populista. Observa-se que essas estratégias articulatórias, contribuem de maneira expressiva para o acúmulo de capital nas mãos de uma pequena parcela da população - a classe dominante.

Em conformidade com a acepção de Azevedo (2001), os estudos concernentes à área em questão, vêm comprovando que "as reformas educacionais operadas mundialmente têm em comum a tentativa de melhorar as economias nacionais pelo fortalecimento dos laços entre escolarização, trabalho, produtividade, serviços e mercado".

Neste sentido têm-se as decisões escolares e as pressões por escolhas que se desvinculam da democracia, pois o sistema educacional está à mercê das políticas neoliberais, que por sua vez se viabilizam sob as imposições do mercado que atuam como uma espécie de força esmagadora das camadas economicamente menos favorecidas.

Como equacionar os problemas de exclusão, desigualdade numa sociedade de classes com interesses antagônicos cerceados pelo capital? Como viabilizar a igualdade e liberdade individual se nesta sociedade a emancipação humana é caracterizada pela participação no mercado globalizado cada vez mais excludente? De que forma a educação perpassa essas relações na tentativa de diminuir as desigualdades sociais oriundas do capitalismo e suas constantes transformações?

\title{
4 A educação entre a cruz e a espada
}

Em matéria de educação brasileira, não poderíamos prescindir da análise não exaustiva da Constituição Federal, que está fundamentada em princípios liberais de forma 


\title{
INTERFACES DA EDUCAÇÃO
}

explícita. Entretanto, a análise não se restringirá apenas a Seção I, Capítulo III, Título VIII, que versa especificamente sobre a Educação, mas estabelecerá vínculos de reflexão no que diz respeito a outros pontos do texto constitucional em que a educação é tratada.

A educação sob os termos legais da legislação principal, é vista de modo contínuo como direito de todos. No início do texto constitucional, no título que trata dos direitos e garantias fundamentais, a educação aparece no art. $6^{\circ}$ como um direito social juntamente com outros direitos "são direitos sociais a educação, a saúde, o trabalho, a moradia, o lazer, a previdência social, a proteção à maternidade e à infância, a assistência aos desamparados, na forma desta Constituição".

Cabe destacar, a título de esclarecimento, que as contradições dentro de uma sociedade liberal se constituem em algo normal, pois fazem parte da sua natureza. Isso posto, cumpre trazer a visão de Eduardo Chaves, liberal ferrenho, que reforça nos dias atuais a idéia de que os denominados direitos sociais, originariamente não são concebidos como direitos, já que "impõem a terceiros deveres positivos que estes não assumiriam livremente e que, portanto, violam a seu direito de agir e de dispor como preferirem de seus bens (no caso de seus recursos financeiros), porque serão obrigados a arcar (com seus impostos) com o custo do atendimento a esses supostos direitos" (CHAVES, 2007, p. 22).

Retomando à Constituição, em um trecho subseqüente, no capítulo VII, tem-se a referência que trata da família, da criança, do adolescente e do idoso. O art. 227 determina que seja dever da família, da sociedade e do Estado, assegurar à criança e ao adolescente, com absoluta prioridade, o direito à educação e outros diversos direitos.

Cunha, realiza uma análise acerca deste assunto.

\begin{abstract}
No texto constitucional ficou patente logo no primeiro artigo que trata da educação (art. 205), que diz ser a educação direito de todos e dever do Estado e da família, devendo ser promovida e incentivada com a colaboração da sociedade. Esta posição vem reforçada por outra que determina seja o ensino ministrado com base no princípio de 'pluralismo de idéias e de concepções pedagógicas', na 'coexistência de instituições públicas e privadas' (art. 206, III). Com isso, atenuouse o dever do estado para com a educação, embora ele venha a ser responsabilizado por providências que a viabilizem, como veremos. No lugar do Estado, ou ao seu lado aparece a família e a sociedade, formas eufemísticas sob as quais os ideólogos do "centrão" ocultaram o nome das sociedades que realmente lhes interessavam, as sociedades comerciais e as sociedades religiosas, - em suma, o privatismo educacional (CUNHA, 2001, p. 445).
\end{abstract}

Nota-se, no entanto, a predominância de uma forma de articulação política que veicula o desmonte sutil do sistema público de educação. A política neoliberal preconiza desarraigar culturalmente o direito à educação como um direito social, haja vista, de acordo com essa visão, os direitos sociais em todos os aspectos não são reconhecidos como direitos verdadeiros, uma vez que enfatizam apenas os chamados direitos individuais.

\section{Considerações Finais}

Em conformidade com os dados levantados durante este breve estudo, pode-se afirmar que são notórias as respostas obtidas às diversas indagações. Apesar da complexidade do assunto, exigir um esforço acurado para a compreensão das contradições que permeiam as relações sociais no contexto (Neo) Liberal, constata-se que cada passo efetuado no decurso da 


\section{INTERFACES DA EDUCAÇÃO}

pesquisa, se constitui em momento marcante, visto que, possibilita o vislumbre de questões obscuras e contraditórias, que ao serem esclarecidas traduziram-se em autênticas descobertas.

Tais descobertas são dotadas de caráter singular e surpreendente, uma vez que revelam a conjuntura real do Estado liberal burguês, que se utiliza do poder político com a finalidade de dominação de classes, fator que o eleva ao posto de grande parasita social, "o Estado se nutre à custa da sociedade e freia seu livre desenvolvimento" (BARSOTTI, 2002, p. 170)

Em seqüência, diversos fatores merecem considerações. Em primeiro plano a pesquisa demonstra que o liberalismo surge em razão da ascensão de uma nova classe social, a burguesia, que nasce dentro da sociedade feudal em contraposição às diversas relações anteriormente estabelecidas, quer sejam de produção, ou social de modo geral. Verifica-se que o ideário liberal surge para justificar a nova forma de produzir a vida, isto é, o modo de produção capitalista em sua forma embrionária, já que neste momento necessitava-se de produzir e vender mercadorias, entretanto, lutar contra as restrições da antiga ordem.

Diante dessa perspectiva, pode-se afirmar que a base material que dá sustentação ao liberalismo é o capitalismo, espécie de estrutura econômica sobre a qual se regulamentam todas as demais relações dentro de contexto social dos homens.

No interior de uma sociedade liberal, liberdade e cidadania se resumem em categorias antitéticas, ao passo que de um lado se concentra cada vez mais a riqueza e de outro a crescente pobreza. Liberdade só existe aos homens de negócio enquanto a cidadania prevista para todos se perde no contraditório caminho da imperante mercantilização de todas as coisas fundamentais às necessidades básicas do ser humano, inclusive da educação ao ser delegada ao privatismo.

$\mathrm{Na}$ tentativa de suprir tais necessidades a maioria da população se vê obrigada a vender a força de trabalho quando possível, haja vista, o capitalismo se constitui em mecanismo excludente de acordo com sua própria natureza. Partindo disso, de que forma as pessoas podem conseguir trabalho no interior dessa relação tão complexa?

Com o intuito de ampliar a liberdade e igualdade às classes populares, a política liberal concebe a educação como o meio mais viável na redução das desigualdades sociais, esquecendo-se de que as mazelas são oriundas do modelo econômico vigente - o capitalismo.

Mediante uma visão mais acurada, contudo, a solução destes impasses não depende diretamente da educação, embora esta possa contribuir de forma bastante expressiva, a partir da luta e avaliação crítica para além da hegemonia do mercado e do lucro, nas relações de ordem econômica e seus mecanismos de exclusão. Ou seja, no âmbito educacional, os educadores não devem permanecer como vestais do sistema educacional excludente, mas, no limite, urge extrair da própria prática alienada o conhecimento necessário contra a hegemonia da ordem exploradora. Portanto, a escola pode mudar e lutar no sentido de neutralizar a transmissão da ideologia dominante via educação, enfim, na medida do possível, devemos impedir que a escola atue como instrumento sociabilizador de tal ideologia.

Constata-se que capitalismo histórico em seu devir transforma tudo e possui um caráter tendencial à mercantilização tanto das coisas materiais quanto da materialização da consciência, isto é, tudo adquire caráter de mercadoria, no caso analisado, a educação como via de produção de capital humano e também meio de empreender um grande negócio lucrativo, portanto, uma mercadoria como outra qualquer.

Isso acentua e exacerba a barbárie do consumismo desenfreado, amiúde desnecessário, fator que conduz o homem ao caminho da exploração em suas múltiplas formas e não a um processo civilizatório imanente a emancipação humana.

A ideologia dominante (Neo) liberal apregoa a igualdade e, de forma mais recente, a equidade, entre os cidadãos, já que o discurso da modernidade ou da pós-modernidade traz 


\section{INTERFACES DA EDUCAÇÃO}

consigo a idéia de "plena cidadania", Estado de direito. Tal processo é inviável dentro da globalização, pois esta não prevê a distribuição/socialização de bens materiais e culturais para todos como um modelo de justiça social.

$\mathrm{Na}$ vida prática, no interior dessa conjuntura, a educação é definida como meio de aguçar e acentuar as desigualdades sociais, visto que a escola forma indivíduos para a competitividade e dessa forma valoriza de modo expresso ou tácito o progresso individual em consonância com o mercado, único meio de obter uma vida "digna".

Enfim, ressalta-se que por meio da avaliação crítica das contradições imanentes ao ideário burguês e sua materialidade histórica é que reside a força não apenas da resistência, mas da disputa no plano da sociedade e da educação. Enfim, não descartamos a viabilidade da contribuição da educação, pois assinalamos que embora seja determinada pelas relações contraditórias já mencionadas pode agir dialeticamente, numa alternativa que visa a uma reversiva reconstrução de uma sociedade fundamentada nos direitos democráticos, na igualdade e na justiça para os excluídos que, por sua vez, são quase todos.

\section{Referências}

AZEVEDO, Janete M. Lins de. A Educação Como Política Pública. 2. ed. Campinas, São Paulo: Autores Associados, 2001.

BARSOTTI, Paulo. Marx, um estatista? A propósito da Comuna de Paris de 1871. In: ORSO, Paulino José; LENER, Fidel; BARSOTTI (Org.). A Comuna de Paris de 1871: história e atualidade. São Paulo: Ícone, 2002.

BOBBIO, NORBERTO. Igualdade e liberdade. 4. ed. Rio de Janeiro: Ediouro, 2000. . A era dos direitos. Rio de Janeiro: Campus, 1992.

. Liberalismo e Democracia. Trad. Marco Aurélio Nogueira. 2. ed. São Paulo:

Brasiliense S. A. 1988.

CHAUI, Marilena. Convite à Filosofia. 13. ed. São Paulo: Ática, 2005.

CHAVES, Eduardo O. C. O Liberalismo na Política, Economia e Sociedade e Suas Implicações para a Educação: uma defesa. In. LOMBARDI, José Claudinei; SANFELICE, José Luís (Org.). Liberalismo e Educação em Debate. Campinas, SP: Autores Associados, Histeber, 2007.

CUNHA, Luiz Antônio. Educação, Estado e Democracia no Brasil. 4. ed. São Paulo: Cortez; Niterói, RJ: Editora da Universidade Federal Fluminense; Brasília, DF: FLACSO do Brasil, 2001.

FRIGOTO, Gaudêncio. Educação e formação humana: ajuste neoconservador e alternativa democrática. In. GENTILI, Pablo A. A.; SILVA, Tomaz Tadeu da (Org.). Neoliberalismo, Qualidade Total e Educação: visões críticas. 3. ed. Petrópolis: Vozes, 1994.

LIMA, Michelle Fernandes; WIHBY, Alessandra; FAVARO, Neide de Almeida Lança Galvão. Liberalismo Clássico: origens históricas e fundamentos básicos. Disponível em: <http: /www.histedbr.fae.unicamp.br>. Acesso em: 20 maio 2009.

MARX, Karl. Prefácio à Crítica da Economia Política. São Paulo: Abril Cultural, 1998.

MELO, Elenir Machado de. Das Utopias do Renascimento às Concepções de Igualdade Social. São Carlos, SP: Programa de Mestrado em Educação da Universidade Federal de São Carlos, 1989. 


\section{INTERFACES DA EDUCAÇÃO}

A democracia, nas concepções de Noberto Bobbio e Robert Paul Wolff. In. SILVA, Ana Lúcia Gomes da et al (Org.). Concepções Pedagógicas: Fundamentos, Metodologias e Didáticas. Campo Grande, MS: UFMS, 2008.

OLIVEIRA, Tatiana Souto Maior de. Gestão do Meio Urbano. Curitiba: IBPEX, 2007.

ORSO, Paulino José. Neoliberalismo: Equívocos e Conseqüências. In. LOMBARDI, José Claudinei; SANFELICE, José Luís (Org.). Liberalismo e Educação em Debate. Campinas, SP: Autores Associados, Histedbr, 2007. 